\title{
Correlation between lateral abdominal, rectus femoris, and triceps brachii muscle thickness and endurance during prone bridge exercise in healthy young adults
}

\author{
Kyeong Bong Lee ${ }^{a}$, Jong Geun Kim ${ }^{b}$, Han Gi Park ${ }^{b}$, Ji Eun Kim ${ }^{b}$, Hye Sun Kim ${ }^{b}$ Wan Hee Lee \\ ${ }^{a}$ Department of Physical Therapy and Rehabilitation, Samsung Medical Center, Seoul, Republic of Korea \\ bepartment of Physical Therapy, College of Health and Welfare, Sahmyook University, Seoul, Republic of Korea \\ 'Department of Physical Therapy, The Graduate School, Sahmyook University, Seoul, Republic of Korea
}

Objective: Prone bridge exercise is one of the core strengthening exercise for improving abdominal, lower and upper extremity muscles. In addition, coactivation of the trunk muscles and extremities is important for treatment of low back pain. This study aimed to investigate the correlation between the thickness, cross-sectional area of the target muscle, and endurance during prone bridge exercise. Our hypothesis was that an increase in muscle thickness is positively related to the hold time for the static prone bridge exercise.

Design: Cross-sectional study.

Methods: Fourteen healthy university students ( 8 men and 6 women) voluntarily participated in the study at Sahmyook University. Hold time for the prone bridge with one and both legs was measured. The resting and contracted thickness of the lateral abdominal, rectus femoris, and triceps muscles was measured using rehabilitative ultrasound imaging. The correlation between muscle thickness and endurance for maintenance time was evaluated.

Results: The prone bridge with both legs and the contraction thickness of the triceps muscle showed a positive correlation $(\mathrm{r}=0.692, p<0.05)$; the prone bridge with one leg and the contraction thickness of the internal oblique and transversus abdominis muscles showed a positive correlation $(\mathrm{r}=0.545,0.574, p<0.05,0.05$, respectively).

Conclusions: Endurance for the prone bridge exercise with a stable support surface is correlated with the contraction thickness of arm muscles; the prone bridge exercise with an unstable support surface is correlated with the contraction thickness of the deep abdominal muscles.

Key Words: Abdominal muscles, Physical endurance, Prone position, Ultrasonography

\section{Introduction}

Core stabilization exercise is a common strategy in sports training and rehabilitation [1]. The aim of this exercise is to improve activation patterns and strengthen the deep abdominal muscles [2]. The trunk muscles are primarily important in performance-related activities, but are also involved in maintaining correct posture. The coactivation of the trunk muscles and the extremities is also believed to be important for treatment and prevention of low back injuries $[3,4]$.

Core stability is defined as the ability of the lumbo-pelvic-hip complex to return to equilibrium following a perturbation, without buckling of the vertebral column [5]. The lateral muscles, external oblique (EO), internal oblique (IO), and transversus abdominis (TrA), for example, provide stability to the lumbar spine during gross body movements and postural adjustment [6,7]. Because abnormal or impaired function of these muscles is related to low back pain (LBP),

Received: 6 April, 2015, 2015 Revised: 25 May, 2015 Accepted: 27 May, 2015

Corresponding author: Wan Hee Lee

Department of Physical Therapy, College of Health and Welfare, Sahmyook University, 815 Hwarang-ro, Nowon-gu, Seoul 139-742, Republic of Korea Tel: 82-2-3399-1633 Fax: 822-3399-1639 E-mail: whlee@syu.ac.kr

(c) This is an Open-Access article distributed under the terms of the Creative Commons Attribution Non-Commercial License (http://creativecommons.org/licens es/by-nc/4.0) which permits unrestricted non-commercial use, distribution, and reproduction in any medium, provided the original work is properly cited.

Copyright $\odot 2015$ Korean Academy of Physical Therapy Rehabilitation Science 
physical therapy has focused on functional improvement of the lateral abdominal muscles $[8,9]$.

The bridge exercise, one of the core stabilization exercises, is a common strategy for improving the coactivation of the abdominal muscles and upper and lower extremities. In particular, the static prone bridge exercise can activate the muscles of the upper and lower extremities, as well as the abdominal, paraspinal, and gluteal musculature, to maintain posture [10]. Moreover, this is both an isometric and wholebody exercise, comprises multiplanar and multi-joint movements, and is safe and effective for multi-joint strengthening.

Rehabilitative ultrasound imaging (RUSI), which allows the visualization of muscle contraction, has been shown to reliably assess the abdominal muscles in various body positions [11]. Measurement of abdominal muscle contraction thickness with RUSI during automatic response is a reliable technique in participants both with and without LBP [12]. In addition, muscle thickness and maximum voluntary contraction of the quadriceps muscle show a significant positive correlation [13]. During the prone bridge exercise, the pectoralis major, anterior deltoid, and triceps brachii, the major muscles of the upper extremity, maintain the prone bridge position [10].

The purpose of this study was to investigate the correlation between muscle thickness and endurance during the prone bridge exercise. Our hypothesis was that an increase in muscle thickness is positively related to hold time for the static prone bridge exercise.

\section{Methods}

\section{Subjects}

Fourteen healthy university students ( 8 men and 6 women) voluntarily participated in this study at Sahmyook University. Inclusion criteria were: (1) no history of LBP for the prior 6 months, (2) no systemic disease that can cause musculoskeletal problems, (3) no deformity or abnormal function that can affect the thickness of abdominal and extremity muscles, and (4) abstinence from physical exercise for 48 hours prior to the examination. Exclusion criteria were: (1) excess alcohol consumption three times a week, (2) use of protein supplements or steroid medications, (3) extreme obesity or very low weight, and (4) inability to complete the entire experimental procedure.

The age of the participants was 24.21 (2.39) years (mean [standard deviation]), the height was $167.96(5.48) \mathrm{cm}$, and the weight was $61.25(8.86) \mathrm{kg}$. The subjects of the study read and signed an informed consent form approved by the local ethics committee.

\section{Study design}

This study used a cross-sectional study design. We measured the thickness of the EO, IO, and TrA muscles at rest, and during the abdominal drawing-in maneuver (ADIM). The cross-sectional area of the rectus femoris and thickness of the triceps brachii were measured with the same protocol, in the resting and contraction state. We measured the duration (seconds) for the prone bridge exercise with one or both legs raised, and investigated the correlation between muscle thickness, cross-sectional area, and the maintenance duration of the prone bridge position.

\section{Experimental procedure}

\section{Measurement of thickness of abdominal muscles}

Participants were instructed to lie supine, with the hip and knee flexed. Lateral abdominal muscle thickness was measured during the end-expiratory phase. Water-soluble transmission gel was applied to the transducer, which was placed just superior to the iliac crest on the dominant side, in the transverse plane along the midaxillary line [14]. Images were captured when the muscle fiber and apex of the $\operatorname{Tr} A$ were clearly visible during the expiratory phase, and adjusted so that the EO, IO, and TrA muscles were visible on the monitor. All subjects learned the ADIM using a pressure biofeedback unit (PBU). Each subject was instructed to take a supine position with the knees bent to $90^{\circ}$, and a PBU (Chattanooga Group Inc., Hixson, TN, USA) was placed under the lumbar spine. Then, the bulb was inflated to $40 \mathrm{~mm}$ $\mathrm{Hg}$, and increased by 0-2 $\mathrm{mmHg}$ while the subject was instructed in the ADIM, as follows [15]. After a few minutes, the subject was instructed to slowly draw in the lower abdomen without moving the spine, ribs, or pelvis. During the ADIM, ultrasound images of the lateral abdominal wall were captured, to calculate the abdominal muscle thickness with the previously described measurement protocol.

\section{Measurement of cross-sectional area of the rectus femoris}

To measure the cross-sectional area of the rectus femoris in the resting state, a water-soluble transmission gel was applied to the transducer, which was placed without any pressure at a point $15 \mathrm{~cm}$ away from the superior base of the patella. Cross-sectional area was measured in three-dimen- 

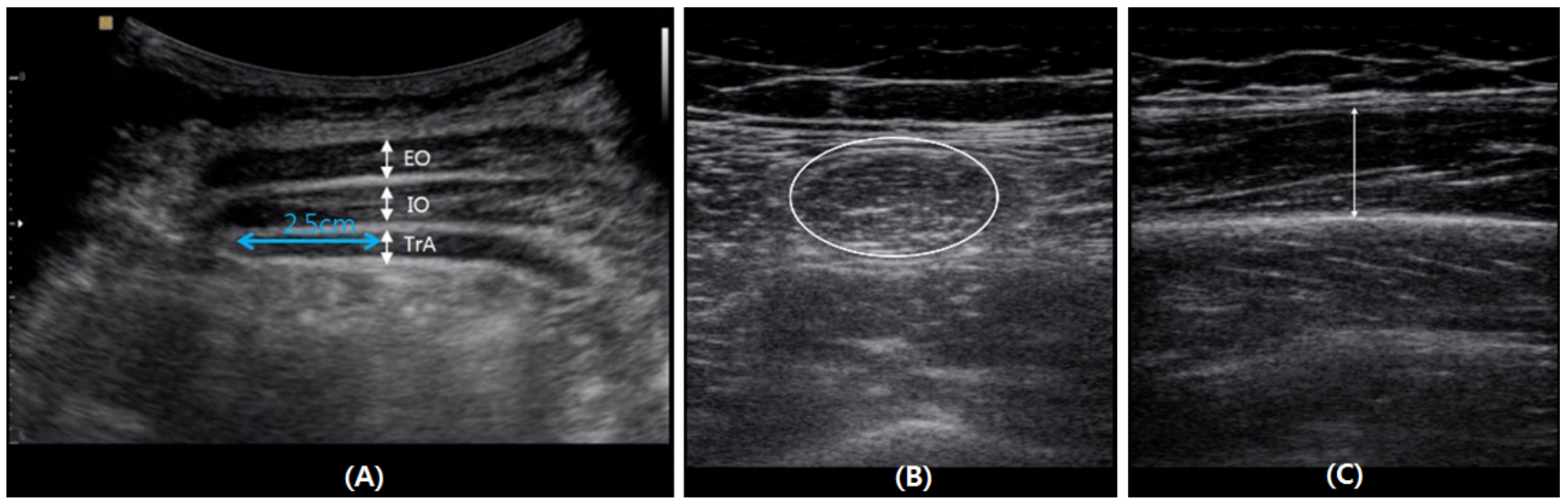

Figure 1. Rehabilitative ultrasound images of lateral abdominal muscle. (A) transverse abdominis (TrA), internal oblique (IO), and external oblique (EO); (B) rectus femoris; and (C) triceps brachii. Circle: cross-sectional area.

sional volume mode, with the transducer oriented in the transverse plane, and images were taken [16]. The contraction state of the rectus femoris was measured with a $5-\mathrm{kg}$ sandbag on the ankle during full knee extension, to induce voluntary contraction. The location of the transducer and the measurement procedure were the same as in the resting state.

\section{Measurement of thickness of the triceps brachii}

The thickness of the triceps brachii was measured at a point $60 \%$ of the distance between the lateral epicondyle of the humerus and the acromial process of the scapula [17]. Triceps brachii thickness was estimated from ultrasound images, with the probe transversally positioned. The muscle thickness was defined as the distance from the interface between the muscle and bone tissue, to the interface between the muscle and fat tissue [18]. Resting triceps brachii thickness was measured with the subject prone on a bed; contraction thickness was measured as the prone subject lowered the arm to the floor and then extended the shoulder to a horizontal position with a $3-\mathrm{kg}$ sandbag on the wrist. RUSI of lateral abdominal muscle, rectus femoris and triceps brachii are in Figure 1.

\section{Maintenance duration of prone bridge posture}

Duration of the prone bridge position was measured with one or both legs raised. The subject would lie prone on the abdomen, with the forearm in contact with the ground, and the trunk slightly raised. Both knees were lifted as a signal was given, and the hold time was measured with a stopwatch. The one-leg position was almost the same, but with the dominant leg raised.

\section{Statistical analysis}

Statistical analyses were performed using PASW Statistics ver. 18.0 software (IBM Co., Armonk, NY, USA). The Kolmogorov-Smirnov test was used to assess the normality of the data. The correlations between muscle thickness, cross sectional area, and hold time of the prone bridge position were determined using Pearson's correlation coefficient. According to a citation for this prior study, $0.00<\mathrm{r}<$ 0.19 represent very weak correlation, $0.20<\mathrm{r}<0.39$ weak, $0.40<\mathrm{r}<0.59$ moderate, $0.60<\mathrm{r}<0.79$ strong and $0.80<\mathrm{r}<$ 1.00 very strong [18]. Values were considered statistically significant at $p<0.05$.

\section{Results}

General characteristics were Table 1, among the subjects on inclusion. The correlations between the maintenance duration of the prone bridge and anthropometrics of the subjects are shown in Table 2. There was no significant correlation between the maintenance duration of the prone bridge exercise with one or both legs raised, but waist circumstance showed a weak correlation with the prone bridge with one leg raised $(\mathrm{r}=0.360)$.

The correlations between muscle thickness, cross-sectional area, and duration of prone plank with one or both legs raised are shown in Tables 3-5. There was a significant correlation between the maintenance duration of the prone bridge exercise and triceps contraction thickness $(\mathrm{r}=0.592$, $p<0.05)$. The maintenance duration of the prone bridge with one leg raised was significantly correlated with the IO 
Table 1. General characteristics and anthropometrics of subjects

\begin{tabular}{lc}
\hline \multicolumn{1}{c}{ Parameter } & Value \\
\hline Gender (male/female) & $8 / 6$ \\
Age $(\mathrm{y})$ & $24.21(2.39)$ \\
Height $(\mathrm{cm})$ & $167.96(5.48)$ \\
Weight $(\mathrm{kg})$ & $61.25(8.86)$ \\
Leg length $(\mathrm{cm})$ & $87.91(2.21)$ \\
Waist circumference $(\mathrm{cm})$ & $75.96(6.36)$ \\
Upper arm circumference $(\mathrm{cm})$ & $28.97(3.05)$ \\
\hline
\end{tabular}

Values are presented as number only or mean (SD). $(\mathrm{r}=0.545, p<0.05)$ and $\operatorname{Tr} \mathrm{A}$ concentric thickness $(\mathrm{r}=0.574$, $p<0.05)$.

\section{Discussion}

The prone bridge is one of the core strengthening exercises, which are intended to improve trunk stability by improving the coactivation of trunk and extremity muscles. The bridge exercise is effective for deep abdominal muscle strengthening and improvement of motor control [19]. It is difficult to increase the contraction of the deep abdominal

Table 2. Correlation between maintenance duration of prone bridge and anthropometrics of subjects

$(\mathrm{N}=14)$

\begin{tabular}{|c|c|c|c|c|c|c|c|c|c|}
\hline \multirow{2}{*}{ Parameter } & \multicolumn{3}{|c|}{ Leg length $(\mathrm{cm})$} & \multicolumn{3}{|c|}{ Waist circumference $(\mathrm{cm})$} & \multicolumn{3}{|c|}{ Upper arm circumference $(\mathrm{cm})$} \\
\hline & Mean (SD) & $\mathrm{r}$ & $p$ & Mean (SD) & $\mathrm{r}$ & $p$ & Mean (SD) & $\mathrm{r}$ & $p$ \\
\hline Prone bridge with both legs & $87.91(2.11)$ & -0.147 & 0.617 & $75.95(6.35)$ & 0.061 & 0.837 & $28.97(3.05)$ & -0.029 & 0.921 \\
\hline Prone bridge with one leg & & 0.083 & 0.778 & & 0.360 & 0.206 & & 0.208 & 0.476 \\
\hline
\end{tabular}

Table 3. Correlations between maintenance duration of prone bridge and resting thickness of lateral abdominal muscles $(\mathrm{N}=14)$

\begin{tabular}{|c|c|c|c|c|c|c|c|c|c|}
\hline \multirow{2}{*}{ Parameter } & \multicolumn{3}{|c|}{ EO resting $(\mathrm{cm})$} & \multicolumn{3}{|c|}{ IO resting $(\mathrm{cm})$} & \multicolumn{3}{|c|}{ TrA resting $(\mathrm{cm})$} \\
\hline & Mean (SD) & $\mathrm{r}$ & $p$ & Mean (SD) & $\mathrm{r}$ & $p$ & Mean (SD) & $\mathrm{r}$ & $p$ \\
\hline Prone bridge with both legs & $0.41(0.15)$ & 0.327 & 0.253 & $0.66(0.23)$ & 0.338 & 0.237 & $0.25(0.09)$ & -0.479 & 0.083 \\
\hline Prone bridge with one leg & & 0.352 & 0.217 & & 0.495 & 0.072 & & -0.250 & 0.389 \\
\hline
\end{tabular}

EO: external oblique, IO: internal oblique, TrA: transverse abdominis.

Table 4. Correlations between maintenance duration of prone bridge and contraction thickness of lateral abdominal muscles

$(\mathrm{N}=14)$

\begin{tabular}{|c|c|c|c|c|c|c|c|c|c|}
\hline \multirow{2}{*}{ Parameter } & \multicolumn{3}{|c|}{ EO contraction $(\mathrm{cm})$} & \multicolumn{3}{|c|}{ IO contraction $(\mathrm{cm})$} & \multicolumn{3}{|c|}{ TrA contraction $(\mathrm{cm})$} \\
\hline & Mean (SD) & $\mathrm{r}$ & $p$ & Mean (SD) & $\mathrm{r}$ & $p$ & Mean (SD) & $\mathrm{r}$ & $p$ \\
\hline Prone bridge with both legs & $0.46(0.17)$ & 0.453 & 0.103 & $0.73(0.21)$ & 0.368 & 0.196 & $0.35(0.09)$ & 0.340 & 0.234 \\
\hline Prone bridge with one leg & & 0.321 & 0.263 & & 0.545 & 0.044 & & 0.574 & 0.032 \\
\hline
\end{tabular}

EO: external oblique, IO: internal oblique, TrA: transverse abdominis.

Table 5. Correlations between maintenance duration of prone bridge and resting, contraction thickness of rectus femoris and triceps brachii

$(\mathrm{N}=14)$

\begin{tabular}{|c|c|c|c|c|c|c|c|c|c|c|c|c|}
\hline \multirow{2}{*}{ Parameter } & \multicolumn{3}{|c|}{ Rectus femoris resting } & \multicolumn{3}{|c|}{$\begin{array}{l}\text { Rectus femoris } \\
\text { contraction }\end{array}$} & \multicolumn{3}{|c|}{ Triceps resting } & \multicolumn{3}{|c|}{ Triceps contraction } \\
\hline & $\begin{array}{l}\text { Mean } \\
(\mathrm{SD})\end{array}$ & $\mathrm{r}$ & $p$ & $\begin{array}{l}\text { Mean } \\
(\mathrm{SD})\end{array}$ & $\mathrm{r}$ & $p$ & $\begin{array}{l}\text { Mean } \\
\text { (SD) }\end{array}$ & $\mathrm{r}$ & $p$ & $\begin{array}{l}\text { Mean } \\
\text { (SD) }\end{array}$ & $\mathrm{r}$ & $p$ \\
\hline Prone bridge with both legs & $\begin{array}{l}1.10 \\
(0.47)\end{array}$ & 0.114 & 0.698 & $\begin{array}{c}2.15 \\
(0.59)\end{array}$ & -0.006 & 0.984 & $\begin{array}{c}0.93 \\
(0.28)\end{array}$ & 0.334 & 0.228 & $\begin{array}{l}1.33 \\
(0.31)\end{array}$ & 0.592 & 0.026 \\
\hline Probe bridge with one leg & & 0.359 & 0.207 & & 0.308 & 0.284 & & 0.280 & 0.333 & & 0.164 & 0.576 \\
\hline
\end{tabular}


muscles with verbal instruction alone; hence, it is important to describe an effective method for prompting an automatic contraction of these muscles.

The prone bridge is an isometric, multi-joint exercise, and simultaneously activates the muscles of the trunk and extremities [20]. Accordingly, we studied the influence of anthropometrics, and resting and contraction muscle thickness, on maintenance duration of the prone bridge position, to determine the correlation between muscle thickness and endurance.

A previous study reported that the highest level of activity in the abdominal muscles is achieved during the prone bridge on a Swiss ball. The study assessed abdominal muscle activity during a prone, side, and supine bridge, on stable and unstable surfaces [19]. Guthrie et al. [21] investigated the ability of two types of bridging-exercise progressions to facilitate the lateral abdominal muscles during an ADIM in individuals with LBP.

Our results showed that arm, waist, and thigh circumference had a very weak to weak correlation with hold time of prone bridge exercise; the explanation for this is that the number of subjects is too small to determine the correlation between anthropometrics and endurance. This study reports that the maintenance duration of the prone bridge is moderately correlated with contraction thickness of the triceps brachii, and that the prone bridge with one leg raised is correlated with IO and TrA contraction thickness. In other words, for the prone bridge position with a stable support surface, there was a greater correlation with contraction thickness of the triceps brachii, than for the IO and TrA, the deep abdominal muscles. However, because the prone bridge with one leg raised is an exercise that uses an unstable support surface, the contraction thickness of the deep abdominal muscles, IO and TrA, has a greater correlation with maintenance duration than the contraction thickness of extremity muscles. Marshall et al. studied whether or not muscle activity measured during advanced Swiss ball exercise was at an approximate intensity recommended for strength or endurance training; they concluded the unstable support surface provided a significant whole-body stimulus [13].

Our study had several limitations requiring future research. First, only healthy young adults were included in this study, and the number of subjects was small; the results are difficult to generalize to patients with LBP. Second, we measured the muscle thickness for the concentric contraction state using RUSI, which cannot be a representative exercise method for the deep abdominal muscles. Third, al- though our methods encourage participants to maintain each of the bridging positions accurately, it is difficult to confirm that the spine and pelvis are aligned perfectly straight during all bridging positions; more precise quantitative devices or methods are needed. Finally, other factors that affect the stability of the lumbo-pelvic region, such as the multifidus spinae, erector spinae, and rectus abdominis, require future investigation.

This study demonstrated that the maintenance duration of the prone bridge exercise with both legs raised is correlated with the contraction thickness of the triceps brachii, and that the exercise with one leg raised is correlated with the contraction thickness of the IO and TrA. Future studies are needed to investigate the correlations between endurance and other variables, to determine the factors that increase endurance for specific exercises.

\section{Conflict of Interest}

The authors declared no potential conflicts of interest with respect to the authorship and/or publication of this article.

\section{References}

1. Wilk BR, Stenback JT, Gonzalez C, Jagessar C, Nau S, Muniz A. Core muscle activation during Swiss ball and traditional abdominal exercises. J Orthop Sports Phys Ther 2010;40:538-9.

2. França FR, Burke TN, Caffaro RR, Ramos LA, Marques AP. Effects of muscular stretching and segmental stabilization on functional disability and pain in patients with chronic low back pain: a randomized, controlled trial. J Manipulative Physiol Ther 2012;35:279-85.

3. Martuscello JM, Nuzzo JL, Ashley CD, Campbell BI, Orriola JJ, Mayer JM. Systematic review of core muscle activity during physical fitness exercises. J Strength Cond Res 2013;27:168498.

4. Nagrale AV, Patil SP, Gandhi RA, Learman K. Effect of slump stretching versus lumbar mobilization with exercise in subjects with non-radicular low back pain: a randomized clinical trial. J Man Manip Ther 2012;20:35-42.

5. Willson JD, Dougherty CP, Ireland ML, Davis IM. Core stability and its relationship to lower extremity function and injury. J Am Acad Orthop Surg 2005;13:316-25.

6. Behm DG, Anderson K, Curnew RS. Muscle force and activation under stable and unstable conditions. J Strength Cond Res 2002;16:416-22.

7. McGill SM. Low back stability: from formal description to issues for performance and rehabilitation. Exerc Sport Sci Rev 2001;29:26-31.

8. Stokes IA, Gardner-Morse MG, Henry SM. Abdominal muscle activation increases lumbar spinal stability: analysis of con- 
tributions of different muscle groups. Clin Biomech (Bristol, Avon) 2011;26:797-803.

9. Hodges PW. Is there a role for transversus abdominis in lumbo-pelvic stability? Man Ther 1999;4:74-86.

10. Marshall PW, Desai I. Electromyographic analysis of upper body, lower body, and abdominal muscles during advanced Swiss ball exercises. J Strength Cond Res 2010;24:1537-45.

11. Linek P, Saulicz E, Wolny T, Myśliwiec A. Reliability of B-mode sonography of the abdominal muscles in healthy adolescents in different body positions. J Ultrasound Med 2014;33:1049-56.

12. Arab AM, Rasouli O, Amiri M, Tahan N. Reliability of ultrasound measurement of automatic activity of the abdominal muscle in participants with and without chronic low back pain. Chiropr Man Therap 2013;21:37.

13. Randhawa A, Wakeling JM. Associations between muscle structure and contractile performance in seniors. Clin Biomech (Bristol, Avon) 2013;28:705-11.

14. Teyhen DS, Miltenberger CE, Deiters HM, Del Toro YM, Pulliam JN, Childs JD, et al. The use of ultrasound imaging of the abdominal drawing-in maneuver in subjects with low back pain. J Orthop Sports Phys Ther 2005;35:346-55.

15. Park DJ, Lee SK. What is a suitable pressure for the abdominal drawing-in maneuver in the supine position using a pressure bio- feedback unit? J Phys Ther Sci 2013;25:527-30.

16. Moreau NG, Teefey SA, Damiano DL. In vivo muscle architecture and size of the rectus femoris and vastus lateralis in children and adolescents with cerebral palsy. Dev Med Child Neurol 2009;51:800-6.

17. Ogasawara R, Thiebaud RS, Loenneke JP, Loftin M, Abe T. Time course for arm and chest muscle thickness changes following bench press training. Interv Med Appl Sci 2012;4:217-20.

18. Matta T, Simão R, de Salles BF, Spineti J, Oliveira LF. Strength training's chronic effects on muscle architecture parameters of different arm sites. J Strength Cond Res 2011;25:1711-7.

19. Czaprowski D, Afeltowicz A, Gębicka A, Pawłowska P, Kędra A, Barrios C, et al. Abdominal muscle EMG-activity during bridge exercises on stable and unstable surfaces. Phys Ther Sport 2014; $15: 162-8$

20. Ekstrom RA, Donatelli RA, Carp KC. Electromyographic analysis of core trunk, hip, and thigh muscles during 9 rehabilitation exercises. J Orthop Sports Phys Ther 2007;37:754-62.

21. Guthrie RJ, Grindstaff TL, Croy T, Ingersoll CD, Saliba SA. The effect of traditional bridging or suspension-exercise bridging on lateral abdominal thickness in individuals with low back pain. $\mathrm{J}$ Sport Rehabil 2012;21:151-60. 